\title{
Damage Caused by Removable Partial Dentures: Reality?
}

\section{Ayman Ellakwa*}

Senior Lecturer, Faculty of Dentistry, The University of Sydney, Australia

As the population of the world ages the need to provide patients with tooth replacement through removable partial dentures is correspondingly increasing.

There are adverse effects that should be kept in mind which might affect the remaining teeth specially, the abutments [1] and the supporting tissues. These effects might extend to the muscles of mastication. We should plan a removable partial dentures (RPDs) without damage to the adjacent teeth or the underlying tissues. So this paper will highlight the possible adverse effects of constructing removable partial dentures.

The relation between the adverse effects of partial dentures on abutment teeth is generally related to the type of the denture wether it has an acrylic or cobalt-chromium (Co-Cr) base. This is important as the ability of a denture to retain plaque is related to the type of denture base; a Co-Cr denture is more hygienic. However the ability of patient to keep the oral hygiene optimal after denture insertion is the main factor which affects the success of removable denture whether it is acrylic or Co-Cr. Accumulation of plaque around and underneath the different components of a partial denture is not only responsible for developing chronic periodontitis but can result in gingival recession and root caries [2-4]. While it is accepted that meticulous oral hygiene instruction plays a major role in decreasing these risks associated with removable partial dentures, the inherent ability of removable partial dentures to retain dental plaque is still considered a major risk factorand might explain the recent link between the prescription of partial dentures and the development of periodontitis around the abutment teeth [1]. This should encourage dental researchers to develop material with low abilities for plaque adhesion.

The question of, should we prescribe partial dentures to patients who already have chronic periodontitis is difficult to answer. Generally speaking patients who are able to demonstrate adequate oral hygiene techniques can wear partial dentures with minimal adverse effects even if they already have chronic periodontitis. These patients should be treated and their periodontitis should be controlled, to perform adequately. The other adverse effects of a partial denture as a result of plaque accumulation is the development of severe inflammation of the underlying tissues developing in denture stomatitis [5] or as a result of direct trauma to the gum might lead to bleeding and bad mouth odour. This type of inflammation is still related to the ability of patients to follow oral hygiene instructions and keep their denture clean and hygienic. RPDs may increase the incidence of caries, damage the periodontium, and increase the amount of stress on natural teeth [4]. These alterations are attributed to poor oral hygiene, increased plaque, calculus accumulation and transmission of excessive forces to the periodontal structures from occlusal surfaces of the framework of RPDs [6]. Many partial denture framework designs contribute to increase an alteration in oral microflora dental plaque accumulation [24]. Rocha et al. [2] and Mihalow and Tinanoff [3] observed an increase in Streptococcus mutans in the saliva of RPD patients after prosthesis placement. This finding suggests that chemoprophylactic strategies need to be established for patients receiving RPDs to control and reduce biofilm formation and caries development, and thereby helping to maintain the patient's oral health [2-4]. Rocha et al. [2] observed alterations in the caries index in RPD users with a higher caries index even in patients with a high level of cooperation and motivation for performing proper oral hygiene. Nevertheless, there is data showing the success of RPD treatment without chemical plaque control [7].

Movement of the denture in and out of the mouth will be a routine performed daily; however, this might lead to direct contact with both soft tissue and tooth structure and with restorative materials. This direct contact could affect the surface of the tooth however there is no clear evidence to support this statement. The direct contact with the denture could also affect the restorative material. Transmission of occlusal load by the denture to the abutment and adjacent soft tissues could also lead to an adverse reaction in the form of ulcers and tooth mobility which can be clearly controlled using a properly deigned denture which in my view favours the use of $\mathrm{Co}-\mathrm{Cr}$ denture using properly placed occlusal rests to prevent downward movement toward tissues and also reduce direct trauma to underlying tissues. Another component of $\mathrm{Co}-\mathrm{Cr}$ denture is the major connector which allows distributing the occlusal load to the adjacent teeth. Using sectional or poorly designed partial dentures has led to unwanted damage to adjacent teeth and also might lead to the unexpected accident of denture swallowing. It is the dentist's responsibility to be aware of the possible damage to the remaining teeth, especially abutments and any damage that might be happening from unexpected inhaling these types of undersized removable partial dentures. Accidental swallowing and aspiration of dental prostheses is not uncommon and has been reported frequently in the literature. The location of a swallowed or aspirated dental prosthesis often is accomplished radiographically but this is difficult with prostheses constructed entirely of acrylic resins. In adults aspiration of teeth and dental restorations is a recognized, yet an infrequent happening in the literature. Main reasons for aspiration are maxillofacial trauma, dental treatment procedures or ethanol intoxication and dementia [8-9]. Therefore removable partial dentures should be designed not only to preserve the remaining teeth but also to prevent accidental swallowing of these appliances.

Manufacturers are advised to increase the radio opacities of these acrylic appliances to facilitate their identification after accidental swallowing or inhalation.

Reported late complications of the undiagnosed swallowed denture include extraluminal migration from the esophagus causing either a diverticulum or perforation (once a perforation has occurred, further severe squeal may be anticipated, e.g. tracheo-oesophageal fistula, the need to resect $18 \mathrm{~cm}$ of ileum, enterocolonic fistula and sigmoid colon perforation [8-12].

The need for a denture base that is hygienic in terms of plaque

*Corresponding author: Dr. Ayman Ellakwa, Senior Lecturer, Faculty of Dentistry The University of Sydney, Westmead Oral Health Centre, Westmead Hospital Darcy Road, Sydney, Australia, Tel: +61298457161; Fax: +61296334759; E-mail: Ayman.ellakwa@ssydney.edu.au

Received March 28, 2012; Accepted March 29, 2012; Published March 30, 2012

Citation: Ellakwa A (2012) Damage Caused by Removable Partial Dentures: Reality?. Dentistry 2:e107. doi:10.4172/2161-1122.1000e107

Copyright: ( 2012 Ellakwa A. This is an open-access article distributed under the terms of the Creative Commons Attribution License, which permits unrestricted use, distribution, and reproduction in any medium, provided the original author and source are credited. 
adhesion and accumulation should be the focus of our research. The ability of the general dentist to motivate and educate the patient for oral hygiene will affect the success of partial dentures. It is the responsibility of the dentist and his ability to collaborate with the technician to properly design the partial dentures to reduce the unwanted forces on the abutment. More research is needed to assess the effect of removable partial dentures and direct retainers on abutment teeth with and without periodontal inflammation.

\section{References}

1. Behr M, Zeman F, Passauer T, Koller M, Hahnel S, et al. (2012) Clinical performance of cast clasp-retained removable partial dentures: a retrospective study. Int J Prosthodont 25: 138-144.

2. Rocha EP, Francisco SB, Del Bel Cury AA, Cury JA (2003) Longitudinal study of the influence of removable partial denture and chemical control on the levels of Streptococcus mutans in saliva. J Oral Rehabil 30: 131-138.

3. Mihalow DM, Tinanoff N (1988) The influence of removable partial dentures on the level of Strepto-coccus mutans in saliva. J Prosthet Dent 59: 49-51.

4. do Amaral BA, Barreto AO, Gomes Seabra E, Roncalli AG, da Fonte Porto Carreiro A, etal. (2010) A clinical follow-up study of the periodontal conditions of RPD abutment and non-abutment teeth. J Oral Rehabil 37: 545-552.
5. Emami E, Taraf H, de Grandmont P, Gauthier G, de Koninck L, et al. (2012) The association of denture stomatitis and partial removable dental prostheses: a systematic review. Int J Prosthodont 25: 113-119.

6. Carlsson GE, Hedegard B, Koivumaa KK (1962) Studies in partial denta prosthesis, III. A longitudinal study of mandibular partial dentures with double extension saddles. Acta Odontol Scand 20: 95-119.

7. Bergman B, Hugoson A, Olsson CO (1995) A 25 year longitudinal study of patients treated with removable partial dentures. J Oral Rehabil 22: 595-599.

8. Cooke LD, Baxter PW (1992) Accidental impaction of partial dental Prostheses in the upper gastrointestinal tract. Br Dent J 172: 451-452.

9. Hodges ED, Durham TM, Stanley RT (1992) Management of aspiration and swallowing incidents: A review of the literature and report of a case. ASDC J Dent Child 59: 413-419.

10. Olak J, Jeyasingham K (1991) Cervical oesophageal diverticulum associated with an impacted denture: a case report. Can J Surg 34: 614-617.

11. Rajesh PB, Goiti JJ (1993) Late onset tracheo-oesophageal fistula following a swallowed dental plate. Eur J Cardiothorac Surg 7: 661-662.

12. Goodacre CJ (1987) A dislodged and swallowed unilateral removable partial denture. J Prosthet Dent 58: 124-125. 